\title{
Prediction of laminar/turbulent transition in airfoil flows
}

\section{Johansen, J.}

Publication date:

1997

\section{Document Version}

Publisher's PDF, also known as Version of record

Link back to DTU Orbit

\section{Citation (APA):}

Johansen, J. (1997). Prediction of laminar/turbulent transition in airfoil flows. Denmark. Forskningscenter Risoe. Risoe-R No. 987(EN)

\section{General rights}

Copyright and moral rights for the publications made accessible in the public portal are retained by the authors and/or other copyright owners and it is a condition of accessing publications that users recognise and abide by the legal requirements associated with these rights.

- Users may download and print one copy of any publication from the public portal for the purpose of private study or research.

- You may not further distribute the material or use it for any profit-making activity or commercial gain

- You may freely distribute the URL identifying the publication in the public portal

If you believe that this document breaches copyright please contact us providing details, and we will remove access to the work immediately and investigate your claim. 


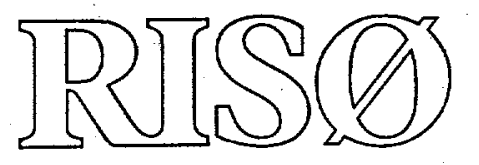

\section{Prediction of Laminar/Turbulent Transition in Airfoil Flows}

Jeppe Johansen

$$
\begin{aligned}
& \text { Juำ } 17999 \\
& \text { OSTI }
\end{aligned}
$$

Risø National Laboratory, Roskilde, Denmark May 1997 


\section{Prediction of Laminar/Turbulent Transition in Airfoil Flows}

Jeppe Johansen

$$
\text { RISO-R-- } 987(E N)
$$

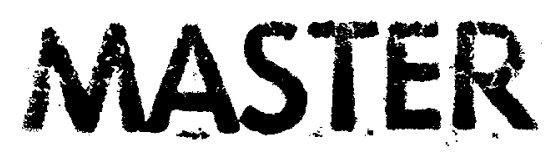

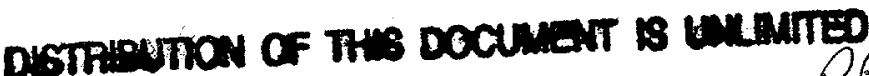

Ris $\varnothing$ National Laboratory, Roskilde, Denmark

May 1997 


\begin{abstract}
The prediction of the location of transition is important for low Reynolds number airfoil flows. The laminar/turbulent properties of the flow field have an important influence on skin friction and separation and therefore on lift and drag characteristics. In the present study the more general $e^{n}$ model, originally proposed by Smith [18] and van Ingen [21], is compared to the Michel criterion [12]. The $e^{n}$ method is based on linear stability analysis employing the Orr-Sommerfeld equation to determine the growth of spatially developing waves. In order not to compute growth rates for each velocity profile, a database, with integral boundary layer parameters as input, has been established. The problem of determining boundary layer properties using a Navier-Stokes solver, is solved using a two-equation integral formulation, which is solved using a direct/inverse Newton-Raphson method. The test cases under investigation are incompressible transitional flow over a flat plate and around airfoils at low and moderate Reynolds numbers, at fixed angles of attack, varying from attached flow through light stall. At high Reynolds numbers no large difference is observed between the two transition models. But for lower Reynolds numbers, the $e^{n}$ method shows better agreement with experiments. Furthermore it has shown to be more stable. It is therefore preferable to the empirical transition model.
\end{abstract}

ISBN $87-550-2308-8$

ISSN $0106-2840$

Information Service Department $\cdot$ Ris $\varnothing \cdot 1997$ 


\section{DISCLAMMER}

Portions of this document may be illegible in electronic image products. Images are produced from the best available original document. 


\section{Contents}

1 Introduction 5

2 Methods 5

2.1 Flow Solver 5

2.2 Transition Prediction Models 6

2.3 Transition Region 7

2.4 Integral Boundary Layer Formulation 8

2.5 Solution Algorithm 9

3 Test Cases 11

3.1 Flat Plate 11

3.2 NACA0012 Airfoil 13

3.3 FX66-S-196 V1 Airfoil 18

4 Conclusion 20

References 21 



\section{Introduction}

Computation of flows past airfoils is a challenging problem due to the various complex phenomena connected with the occurrence of separation bubbles and the onset of turbulence. In many engineering applications involving a fully turbulent flow with only weak streamwise pressure gradients and small curvature effects, turbulent quantities can be predicted well using conventional turbulence models. In the case of low Reynolds number airfoil flows $\left(R e<\approx 10^{6}\right)$, proper modeling of the transition point location is crucial for predicting leading edge separation. The transition prediction algorithm must be reliable since the transition point location may affect the termination of a transitional separation bubble and hence determine bubble size and associated losses. This again has a strong influence on the airfoil characteristics, with drag being the most affected.

Investigating leading edge separation, the upstream influence is important. Boundary layer theory is based on the assumption that the shear layer grows slowly in the general flow direction. As a consequence the upstream transport of momentum and streamwise gradients of viscous and turbulent stresses is not accounted for. These stresses are generally negligible for high Reynolds number flows, but for low Reynolds number flows the upstream influence has to be accounted for. For separated flows, where the shear layer is neither thin nor slender, the Navier-Stokes equations should be used.

A popular transition prediction model is the empirical criterion by Michel [12]. As shown by e.g. Ekaterinaris et al. [8] and Mehta et al. [10], this model gives fairly good results for many airfoil flows. In the present study the more general $e^{n}$ method, proposed originally by Smith [18] and van Ingen [21], is compared to the Michel criterion. The $e^{n}$ method is based on linear stability analysis using the Orr-Sommerfeld equation to determine the growth of spatially developing waves. There have been several attempts to apply simplified versions of the $e^{n}$ method in combination with viscous-inviscid interaction procedures (e.g. Drela and Giles [7] and Cebeci [4]). To avoid computing growth rates for each velocity profile, a database with integral boundary layer parameters as input has been established. To the authors' knowledge, no successful attempt has been made until now to use the $e^{n}$ method in combination with a Navier-Stokes (N-S) solver. This has been achieved in the present work.

\section{Methods}

\subsection{Flow Solver}

The results obtained in the present work are computed using EllipSys2D, a general purpose Navier-Stokes solver in 2-D based on the Reynolds-averaged incompressible flow equations in primitive variables $(u, v, p)$. The code has been developed by Michelsen and Sørensen [13, 14, 19]. The system of equations is solved with the SIMPLE method for steady-state calculations. Solution of the transport equations is obtained using a second-order upwind scheme.

The steady-state calculations are accelerated by the use of local time stepping and a three-level grid sequence.

The turbulence model employed is the two-equation $k-\omega$ Shear Stress Transport (SST) turbulence model by Menter [11], who obtained good predictions for flows with adverse pressure gradients. The $k-\omega S S T$ turbulence model is therefore appropriate for airfoil flows. 


\subsection{Transition Prediction Models}

In the present study, two different transition prediction models are used. These are the empirical one-step model of Michel [12] and the semi-empirical $e^{n}$ model based on linear stability in the form of a database [20]. The Michel criterion is a simple model based on experimental data and correlates local values of momentum thickness with position of the transition point. It simply states that the transition onset location takes place where

$$
R e_{\theta}=2.9 R e_{x}^{0.4}
$$

where $R e_{x}$ is the Reynolds number based on the distance measured from the stagnation point.

The second model is based on linear stability theory and is referred to as the $e^{n}$ model by Smith [18] and van Ingen [21]. The version used here is that of Stock and Degenhart [20], based on a simplified interpolation method.

Linear stability theory suggests that the unperturbed steady and parallel mean flow is superimposed with a time-dependent sinusoidal perturbation - the TollmienSchlichting waves. This results in the well known Orr-Sommerfeld equation, which is a 4 th order linear eigenvalue problem in $\phi$, where $\phi$ is the amplitude of the perturbation. This equation determines whether spatially developing waves will be stable or unstable due to the amplification factor $\alpha_{i}$, which is the imaginary part of the spatial wave number. In this way the point of instability can be determined. The $e^{n}$ model predicts turbulence when the amplitude of the most unstable frequency exceeds the initial unstable amplitude by a factor $e^{n}$. The $n$ factor is empirically determined from several experimental data, and can vary from one flow situation to another. It is usually set at a value around 8-10. In the present work it is set at 9 . For further details about the $e^{n}$ model see [3], [18], and [21].

Stock and Degenhart suggest building up a database within which instability data can be evaluated. The approach is based on the idea that a discrete set of results to the Orr-Sommerfeld equation is representative for all possible laminar velocity profiles and for all relevant disturbance frequencies. As input the Orr-Sommerfeld equation the Falkner-Skan velocity profiles and their second derivatives are used. The instability data are stored in a database from which the relevant information can be extracted by interpolation.

In figure 1 the process of determining the $n$ factor is depicted.

In the top graph of figure 1 the neutral curve obtained from the Orr-Sommerfeld equation is shown, $\left(\alpha_{i}=0\right) . F$ is the reduced frequency, $R e_{\delta}$. is the Reynolds number based on displacement thickness, and $\alpha_{i}$ is the amplification factor of the perturbations in spatial stability theory. Sweeping through the neutral curve for different values of $F, F_{1}$, The $N$ factor can be determined for each frequency using

$$
N\left(F_{1}, R e_{\delta^{*}}\right)=-\int_{R e_{\delta_{m i n}}}^{R e_{\delta^{*}}} \alpha_{i} d R e_{\delta^{*}},
$$

resulting in a number of $N$ curves as the one depicted in the lower graph of figure 1 . The envelope of all $N$ curves results in a $n_{\max }$ curve, which can be used to determine the point of transition i.e. where the $n_{\max }$ curve reaches the value of 9 .

Having computed a velocity field using the N-S solver, it is possible to determine laminar boundary layer integral parameters such as displacement thickness, $\delta^{*}$, momentum thickness, $\theta$, and kinetic energy thickness, $\delta_{3}$. These values are used as input to the database and the stability characleristics are evaluated by interpolation. The database is originally implemented by Petersen [16] using Falkner-Skan 


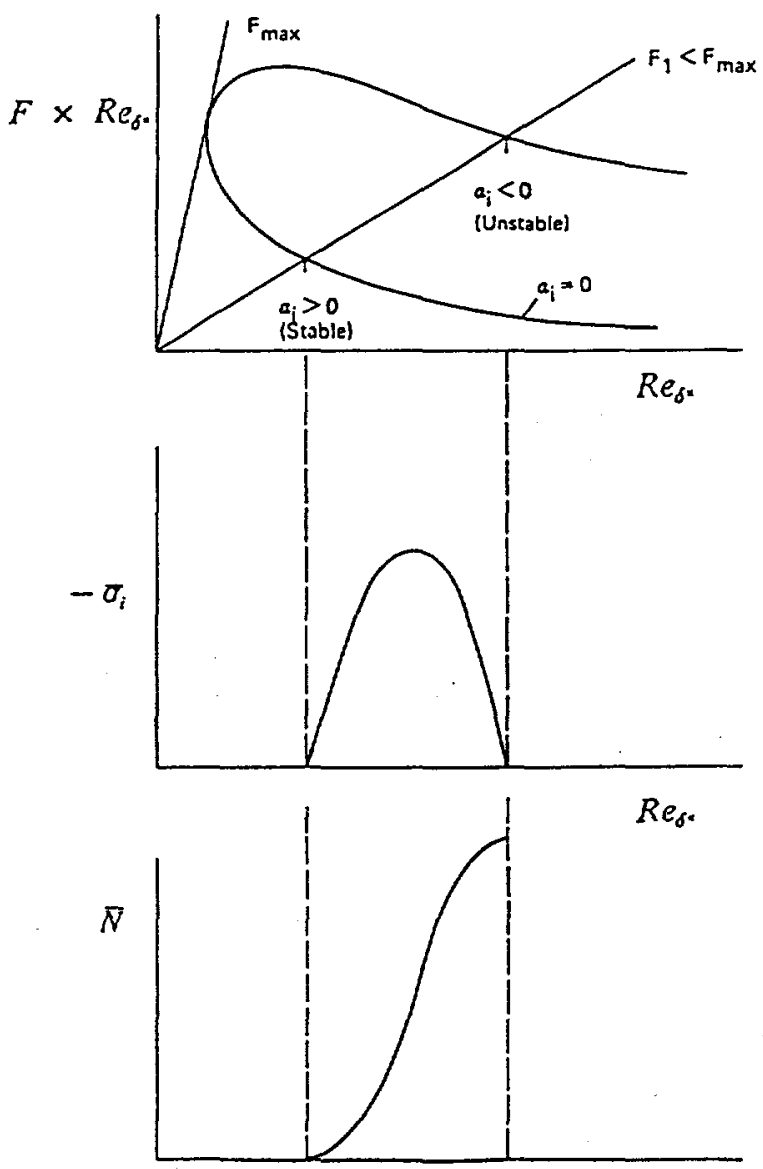

Figure 1. Diagrammatic sketch of the neutral curve, the amplification factor $\alpha_{i}$, and the integrated $N$ factor for a boundary layer with a constant value of shape factor $H$. From [20]

velocity profiles and is extended by Olesen [15] to include separated velocity profiles, based on the theory of Dini et al. [6], who uses velocity profiles described by hyperbolic tangent functions.

\subsection{Transition Region}

The extension of the transition region is obtained by an empirical model, suggested by Chen and Thyson [5], which is a conceptually simple model that scales the eddy viscosity by a intermittency function varying from zero in the laminar region and progressively increases in the transitional region until it reaches unity in the fully turbulent region. The intermittency function, $\gamma_{t r}$, is given by

$$
\gamma_{t r}(x)=1-\exp \left[\left(-\frac{U^{3}}{\nu^{2} G_{\gamma_{t r}}}\right) \operatorname{Re}_{x t r}{ }^{-1.34}\left(x-x_{t r}\right) \int_{x_{t r}}^{x} \frac{d x}{U}\right]
$$

The modeling constant, $G_{\gamma_{t r}}$ was originally suggested to be 1200 for high Reynolds number flows. This has been modified by Cebeci, [4], for low Reynolds number flows, in order to take into account separation.

$$
G_{\gamma_{t r}}=213\left[\log \left(R e_{x_{t r}}\right)-4.732\right] / 3
$$

The range where this modification is valid is $R e_{c}=2.4 \times 10^{5}$ to $2 \times 10^{6}$. 


\subsection{Integral Boundary Layer Formulation}

The input parameters for the database are the laminar boundary layer parameters, $\delta^{*}, \theta$, and $\delta_{3}$ together with the free-stream velocity $u_{e}$ and the Reynolds number based on chord length, $R e_{c}$. This results in some difficulties. Firstly, the determination of boundary layer parameters using the N-S solver is not accurate, since the boundary layer thickness is not well defined. Secondly, the turbulence starting from the transition point influences the integral parameters upstream. This results in boundary layer parameters differing from their fully laminar value resulting in erroneous interpolation in the database. An alternative procedure is thus required for calculating these parameters.

The procedure chosen in the present study is a two equation integral model based on dissipation closure. The two equations are the von Karman integral relation given by:

$$
\frac{d \theta}{d \xi}+(2+H) \frac{\theta}{u_{e}} \frac{d u_{e}}{d \xi}=\frac{C_{f}}{2},
$$

where $\theta$ is the momentum thickness, $H$ is the shape factor, $u_{e}$ is the velocity at the boundary layer edge, $\xi$ is the streamwise coordinate, and $C_{f}$ is the skin friction coefficient. The second equation is a combination of equation 5 and the kinetic energy thickness equation, (see [17]), and is given by:

$$
\theta \frac{d H^{*}}{d \xi}+H^{*}(1-H) \frac{\theta}{u_{e}} \frac{d u_{e}}{d \xi}=2 C_{D}-H^{*} \frac{C_{f}}{2},
$$

where $H^{*}$ is the kinetic energy shape parameter and $C_{D}$ is the dissipation coefficient. For laminar flow, the two ordinary first order differential equations can be solved with the following closure relationships for $H^{*}, C_{f}$, and $C_{D}$ respectively.

$$
\begin{array}{rlrl}
H^{*} & =1.515+0.076 \frac{(4-H)^{2}}{H}, & & H<4 \\
H^{*} & =1.515+0.040 \frac{(H-4)^{2}}{H}, & H>4 \\
\operatorname{Re}_{\theta} \frac{C_{f}}{2}= & -0.067+0.01977 \frac{(7.4-H)^{2}}{(H-1)}, & H<7.4 \\
\operatorname{Re}_{\theta} \frac{2 C_{D}}{H^{*}} & =0.207+0.00205(4-H)^{5.5}, & H<4 \\
\operatorname{Re}_{\theta} \frac{2 C_{D}}{H^{*}} & =0.207-0.003 \frac{(H-4)^{2}}{\left(1+0.02(H-4)^{2}\right)}, & & H>4
\end{array}
$$

This model has successfully been used by Drela and Giles and for further details is referred to [7].

To solve the two equations, 5 and 6 , a third relation is necessary. Using the Bernoulli equation along a streamline to determine $u_{e}$ and assuming no pressure variation across the boundary layer $\left(p_{\text {wall }}=p_{\text {edge }}\right)$, the two equations can be solved directly by a Newton-Raphson method. When approaching separation, the direct procedure becomes ill-conditioned because a single edge velocity corresponds to two different skin friction factors. By computing $C_{f}$ using the N-S solver, $H$ can be computed using the closure relation 8 , and the two equations can be solved inversely with $\theta$ and $u_{e}$ as variables. Close to stagnation point, where the skin friction varies dramatically and a small variation in skin friction factor causes a large variation in edge velocity, the inverse procedure fails to converge. 


\subsection{Solution Algorithm}

As mentioned above the integral boundary layer equations are solved using a Newton-Raphson method for nonlinear systems of equations, due to the strong coupling. If the system of equations is given by

$$
\mathbf{F}(\mathbf{x})=\mathbf{0}
$$

where $\mathbf{F}$ denotes the vector of functions and $\mathbf{x}$ denote the vector of independent variables, the solution of equation 10 is given by

$$
\mathbf{x}_{\text {new }}=\mathbf{x}_{\text {old }}+\delta \mathbf{x}
$$

$\delta \mathbf{x}$ are the corrections to the old solution obtained from the following matrix equation

$$
\mathbf{J} \delta \mathbf{x}=-\mathbf{F} .
$$

Here $\mathbf{J}$ is the Jacobian matrix given by

$$
J_{i j} \equiv \frac{\delta F_{i}}{\delta x_{j}}
$$

\section{Direct solution procedure}

If free stream velocity, $u_{e}$, is determined by the N-S solver, the two remaining parameters, $H$ and $\theta$ can be computed solving equations 5 and 6 directly. This results in the following discretized equations.

$$
\begin{aligned}
f_{1}= & \frac{\theta_{i}-\theta_{i-1}}{\xi_{i}-\xi_{i-1}}+\left(2+\frac{H_{i}+H_{i-1}}{2}\right) \frac{\theta_{i}+\theta_{i-1}}{u_{e_{i}}+u_{e_{i-1}}} \frac{u_{e_{i}}-u_{e_{i-1}}}{\xi_{i}-\xi_{i-1}}-\left.\frac{C_{f}}{2}\right|_{i-\frac{1}{2}}=0 \\
f_{2}= & \frac{\theta_{i}+\theta_{i-1}}{2} \frac{d H^{*}}{d H} \frac{H_{i}-H_{i-1}}{\xi_{i}-\xi_{i-1}}+\left.H^{*}\right|_{i-\frac{1}{2}}\left(1-\frac{H_{i}+H_{i-1}}{2}\right) \frac{\theta_{i}+\theta_{i-1}}{u_{e_{i}}+u_{e_{i-1}}} \frac{u_{e_{i}}-u_{e_{i-1}}}{\xi_{i}-\xi_{i-1}} \\
& -\left.2 C_{D}\right|_{i-\frac{1}{2}}+\left.\left.H^{*}\right|_{i-\frac{1}{2}} \frac{C_{f}}{2}\right|_{i-\frac{1}{2}}=0
\end{aligned}
$$

$H^{*}, \frac{C_{f}}{2}$, and $2 C_{D}$ are given by relationships 7,8 , and 9 respectively.

The chain rule is used for

$$
\frac{d H^{*}}{d \xi}=\frac{d H^{*}}{d H} \frac{d H}{d \xi}
$$

where

$$
\begin{array}{ll}
\frac{d H^{*}}{d H}=0.076\left(1-\frac{16}{\left(\frac{H_{i}+H_{i-1}}{2}\right)^{2}}\right), & H<4 \\
\frac{d H^{*}}{d H}=0.040\left(1-\frac{16}{\left(\frac{H_{i}+H_{i-1}}{2}\right)^{2}}\right), & H>4 .
\end{array}
$$

For the direct solution procedure the matrix equation 12 is given by

$$
\left(\begin{array}{cccc}
\frac{d f_{1}}{d \theta_{i-1}} & \frac{d f_{1}}{d H_{i}-1} & \frac{d f_{1}}{d \theta_{i}} & \frac{d f_{1}}{d H_{i}} \\
\frac{d f_{2}}{d \theta_{i-1}} & \frac{d f_{2}}{d H_{i-1}} & \frac{d f_{2}}{d \theta_{i}} & \frac{d f_{2}}{d H_{i}}
\end{array}\right)\left(\begin{array}{c}
\delta \theta_{i-1} \\
\delta H_{i-1} \\
\delta \theta_{i} \\
\delta H_{i}
\end{array}\right)=-\left(\begin{array}{c}
f_{1} \\
f_{2}
\end{array}\right)
$$

Since the parameters at the previous boundary layer station is already computed resulting in $\delta \theta_{i-1}$ and $\delta H_{i-1}=0$, equation 17 is reduced to the following very simple system of equations. 


$$
\left(\begin{array}{ll}
\frac{d f_{1}}{d \theta_{i}} & \frac{d f_{1}}{d H_{i}} \\
\frac{d f_{2}}{d \theta_{i}} & \frac{d f_{2}}{d H_{i}}
\end{array}\right)\left(\begin{array}{c}
\delta \theta_{i} \\
\delta H_{i}
\end{array}\right)=-\left(\begin{array}{c}
f_{1} \\
f_{2}
\end{array}\right)
$$

where

$$
\begin{aligned}
\frac{d f_{1}}{d \theta_{i}} & =\frac{1}{\xi_{i}-\xi_{i-1}}+\left(2+\frac{H_{i}+H_{i-1}}{2}\right) \frac{u_{e_{i}}-u_{e_{i-1}}}{u_{e_{i}}+u_{e_{i-1}}} \frac{1}{\xi_{i}-\xi_{i-1}}-\frac{d \frac{C_{f}}{2}}{d \theta_{i}} \\
\frac{d f_{1}}{d H_{i}} & =\frac{1}{2} \frac{\theta_{i}+\theta_{i-1}}{u_{e_{i}}+u_{e_{i-1}}} \frac{u_{e_{i}}-u_{e_{i-1}}}{\xi_{i}-\xi_{i-1}}-\frac{d \frac{C_{f}}{2}}{d H_{i}} \\
\frac{d f_{2}}{d \theta_{i}}= & \frac{1}{2} \frac{d H^{*}}{d H} \frac{H_{i}-H_{i-1}}{\xi_{i}-\xi_{i-1}}+\left.H^{*}\right|_{i-\frac{1}{2}}\left(1-\frac{H_{i}+H_{i-1}}{2}\right) \frac{u_{e_{i}}-u_{e_{i-1}}}{u_{e_{i}}+u_{e_{i-1}}} \frac{1}{\xi_{i}-\xi_{i-1}} \\
& -\frac{d 2 C_{D}}{d \theta_{i}}+\left.H^{*}\right|_{i-\frac{1}{2}} \frac{d \frac{C_{f}}{2}}{d \theta_{i}}
\end{aligned}
$$

and

$$
\begin{aligned}
\frac{d f_{2}}{d H_{i}}= & \frac{\theta_{i}+\theta_{i-1}}{2}\left(\frac{d H^{*}}{d H}-0.076 \cdot 16 \cdot 2 \frac{1}{\left(\frac{H_{i}+H_{i-1}}{2}\right)^{3}} \frac{H_{i}-H_{i-1}}{\xi_{i}-\xi_{i-1}}\right) \\
& +\frac{\theta_{i}+\theta_{i-1}}{u_{e_{i}}+u_{e_{i-1}}} \frac{u_{e_{i}}-u_{e_{i-1}}}{\xi_{i}-\xi_{i-1}}\left(-\left.\frac{H^{*}}{2}\right|_{i-\frac{1}{2}}+\frac{d H^{*}}{d H}\left(1-\frac{H_{i}+H_{i-1}}{2}\right)\right) \\
& -\frac{d 2 C_{D}}{d H_{i}}+\frac{d H^{*}}{d H} \frac{C_{f}}{2}+\left.H^{*}\right|_{i-\frac{1}{2}} \frac{d \frac{C_{f}}{2}}{d H_{i}}
\end{aligned}
$$

This system of equations is a simple $2 \times 2$ system and is solved using Cramers rule.

\section{Inverse solution procedure}

As the flow approaches separation the integral boundary layer equations are solved inversely with $\theta$ and $u_{e}$ as the independent variables. The skin friction, $C_{f}$ can be determined using the N-S solver and from relationship 8 , the shape factor $H$ is computed. The discretized equations, 14, are equal to those for the direct procedure. For the inverse solution procedure the matrix equation 12 is given by

$$
\left(\begin{array}{cc}
\frac{d f_{1}}{d \theta_{i}} & \frac{f_{1}}{d u_{e_{i}}} \\
\frac{d f_{2}}{d \theta_{i}} & \frac{f_{2}}{d u_{e_{i}}}
\end{array}\right)\left(\begin{array}{c}
\delta \theta_{i} \\
\delta u_{e}
\end{array}\right)=-\left(\begin{array}{c}
f_{1} \\
f_{2}
\end{array}\right)
$$

where

$$
\begin{gathered}
\frac{d f_{1}}{d \theta_{i}}=\frac{1}{\xi_{i}-\xi_{i-1}}+\left(2+\frac{H_{i}+H_{i-1}}{2}\right) \frac{u_{e_{i}}-u_{e_{i-1}}}{u_{e_{i}}+u_{e_{i-1}}} \frac{1}{\xi_{i}-\xi_{i-1}} \\
\frac{d f_{1}}{d u_{e_{i}}}=\left(2+\frac{H_{i}+H_{i-1}}{2}\right) \frac{\theta_{e_{i}}+\theta_{e_{i-1}}}{\xi_{i}-\xi_{i-1}} \frac{2 u_{e_{i-1}}}{\left(u_{e_{i}}+u_{e_{i-1}}\right)^{2}} \\
\frac{d f_{2}}{d \theta_{i}}=\left.\frac{u_{e_{i}}-u_{e_{i-1}}}{u_{e_{i}}+u_{e_{i-1}}} \frac{1}{\xi_{i}-\xi_{i-1}} H^{*}\right|_{i-\frac{1}{2}}\left(1-\frac{H_{i}+H_{i-1}}{2}\right)+\frac{1}{2} \frac{d H^{*}}{d H} \frac{H_{i}-H_{i-1}}{\xi_{i}-\xi_{i-1}}-\frac{d 2 C_{D}}{d \theta_{i}} \\
\text { and } \\
\frac{d f_{2}}{d u_{e_{i}}}=\left.\frac{\theta_{i}+\theta_{i-1}}{\xi_{i}-\xi_{i-1}} H^{*}\right|_{i-\frac{1}{2}}\left(1-\frac{H_{i}+H_{i-1}}{2}\right) \frac{2 u_{e_{i-1}}}{\left(u_{e_{i}}+u_{e_{i-1}}\right)^{2}}-\frac{d 2 C_{D}}{d u_{e_{i}}}
\end{gathered}
$$

The derivatives of $\frac{C_{f}}{2}$ and $2 C_{D}$ are rather lengthy but straightforward. 
The solution algorithm is as follows: Starting at the stagnation point and marching in $\xi$-direction, the direct Newton-Raphson procedure is applied. Before separation $\left(H_{\text {sep }}=3.9\right)$, when the shape factor $H$ reaches a value of 3.0 , the inverse procedure is applied. This procedure determines integral parameters, avoiding the use of velocity profiles and definition of $u_{e}$. Furthermore, the values can be determined using only a few iterations due to the Newton-Raphson procedure.

The laminar closure on $C_{f}$ results in a lower limit of $C_{f}$, which corresponds to $H=7.4$, where the flow is well separated. In the present study it is assumed that if $H$ reaches 7.4, the flow should be considered as becoming turbulent. This is a reasonable assumption, supported by the fact that the $\mathrm{N}$-factor in these situations approaches the empirical value, 9 . The computation is stopped when either the $n$ factor reaches the value of 9 or the shape factor reaches the value of 7.4 .

\section{Test Cases}

In order to validate the transition models, flow over a flat plate is investigated, since this is a relatively simple transitional flow, and experimental data are available.

The airfoils tested are chosen because good experimental data are available including transitional information. The thin symmetric NACA0012 airfoil, where curvature effects are relatively small, is chosen. Experimental data are available from Gregory et al. [9] and Abbott et al. [1]. To also check the models, for more moderate Reynolds number and where larger curvature effects are present, the $19 \%$ thick laminar Wortmann airfoil FX66-S-196 V1 from Stuttgarter Profilkatalog [2], is chosen.

The computations are carried out assuming steady state conditions in order to take advantage of the local time stepping procedure.

\subsection{Flat Plate}

The simplest transitional flow is the flow over a flat plate. Almost no pressure gradient is present and a large amount of experimental data exist. The critical Reynolds number, which is defined as where the flow turns from laminar to turbulent is a function of the turbulence intensity. But for the present computation the turbulence intensity is in practice negligible and the critical Reynolds number is given by $R e_{c r}=2.8 \times 10^{6}$ and the Reynolds number where the flow has become fully turbulent is $R e_{t}=3.9 \times 10^{6}$ [17].

The flat plate is modelled as a plate with a finite thickness. The leading edge is describes as a parabola and the trailing edge is made by collapsing the two last points into one. The thickness of the plate is 0.002 chord length and the parabola is extended 10 thicknesses from the leading edge. The grid around the flat plate is an o-mesh with $288 \times 48$ gridpoints in streamwise an normal direction respectively.

Figure 2 shows the shape factor, $H$ and the growth of the $n$ factor, $n_{\max }$ as one proceeds downstream. The transition takes place where the $n$ factor reaches the value 9 . The resulting transition point corresponds to a critical Reynolds number, $R e_{c r}=1.8 \times 10^{6}$.

Figure 3 shows the intermittency function determined by equation 4 . It is seen that the flow is considered fully turbulent at $\approx 0.9$ corresponding to $R e_{t}=2.7 \times$ $10^{6}$.

Figure 4 shows the skin friction factor, $C_{f}$ for fully turbulent flow as well as for transitional flow using both $e^{n}$ and Michel models. It is observed that using 


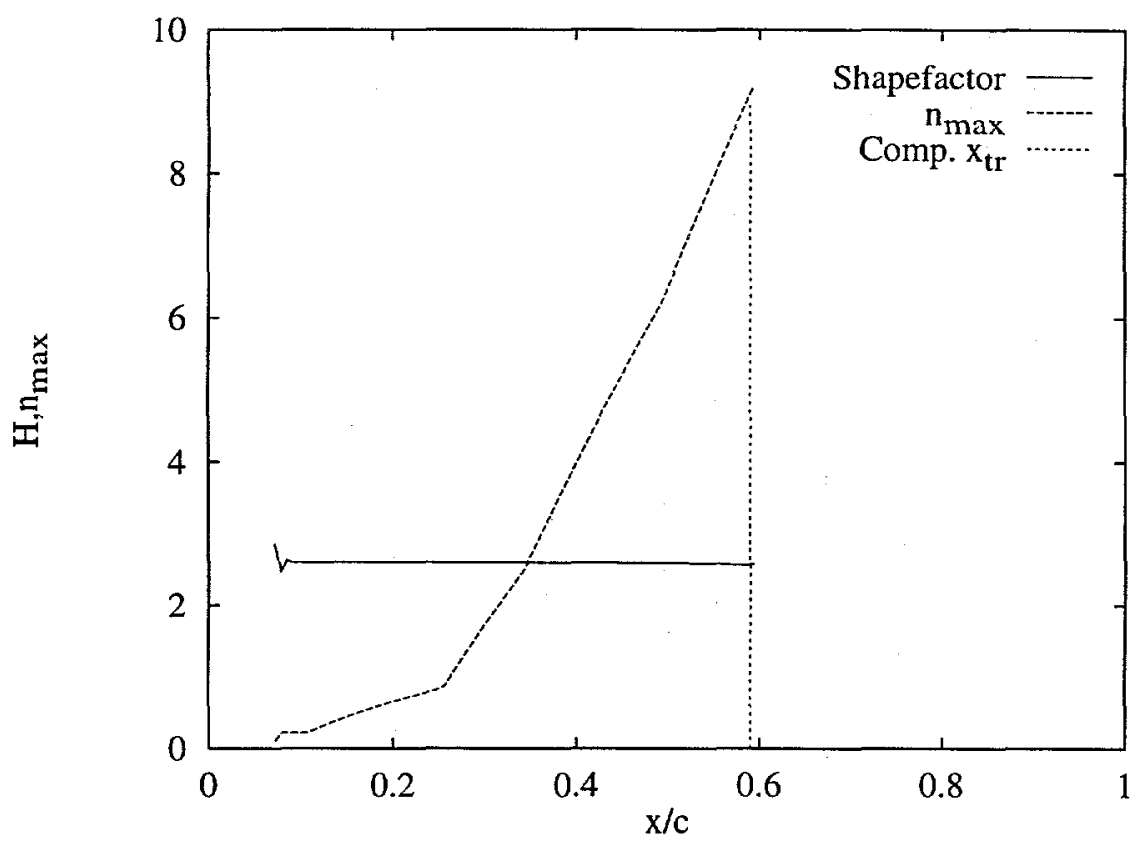

Figure 2. Flow over a flat plate. Shape factor, $H, n_{\max }$, and transition point location, $x_{t r}, R e=3 \times 10^{6}$

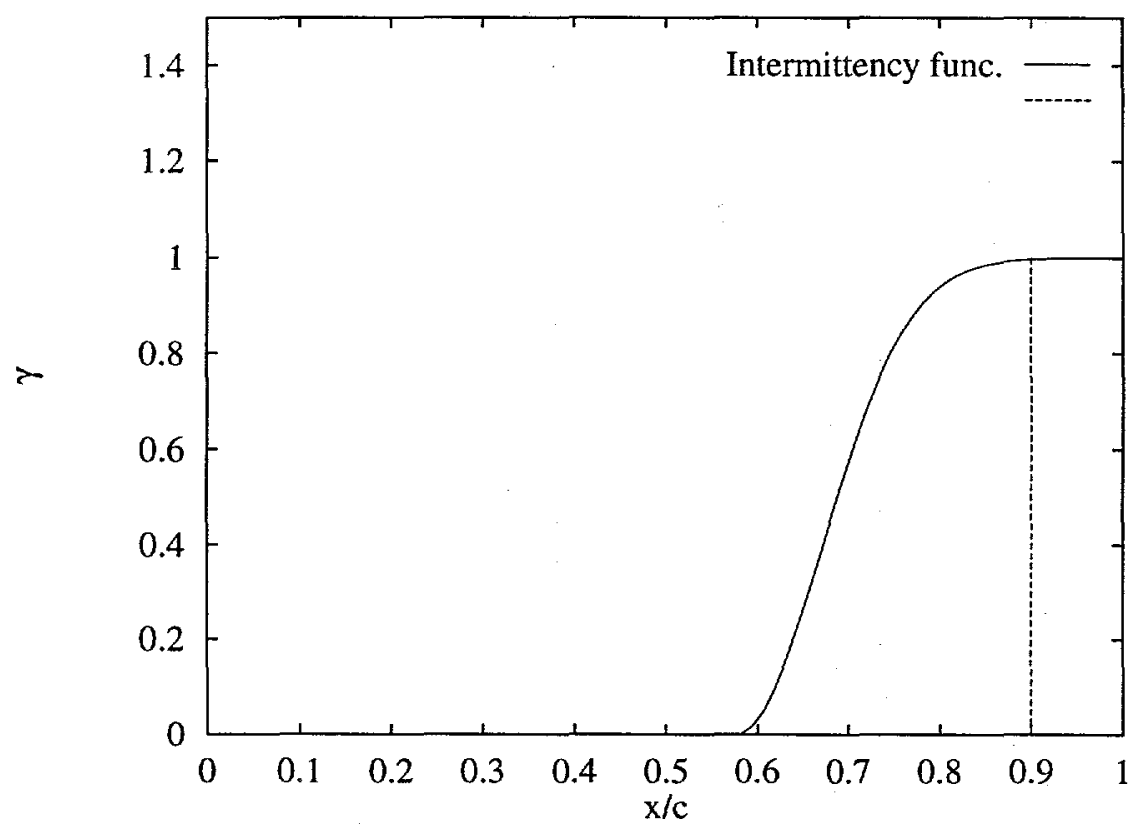

Figure 3. Flow over a flat plate. Intermittency function; $\gamma \cdot R e_{c r}=1.8 \times 10^{6}$, $R e_{t}=2.7 \times 10^{6}$

the Michel criterion, transition is predicted slightly upstream corresponding to $R e_{c r}=1.5 \times 10^{6}$ and $R e_{t}=2.5 \times 10^{6}$. 


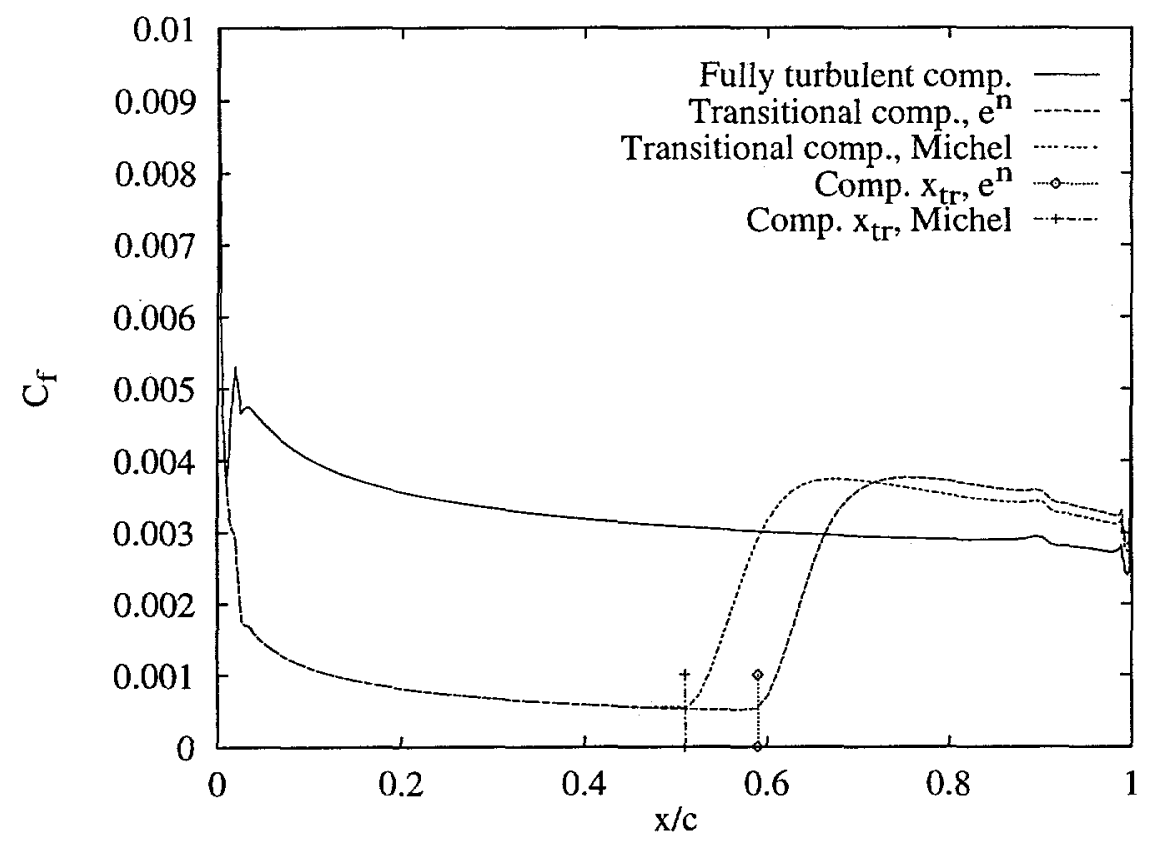

Figure 4. Flow over a flat plate. Comparison between Fully turbulent and transitional flow using both $e^{n}$ and Michel model. Skin friction and, $C_{f}$, transition point location, $x_{t r}, R e=3 \times 10^{6}$

\subsection{NACA0012 Airfoil}

For each airfoil a grid refinement study is carried out resulting in a $288 \times 96$ grid for both airfoils. The grid spacing to the first gridline is $y^{+} \approx 2$.

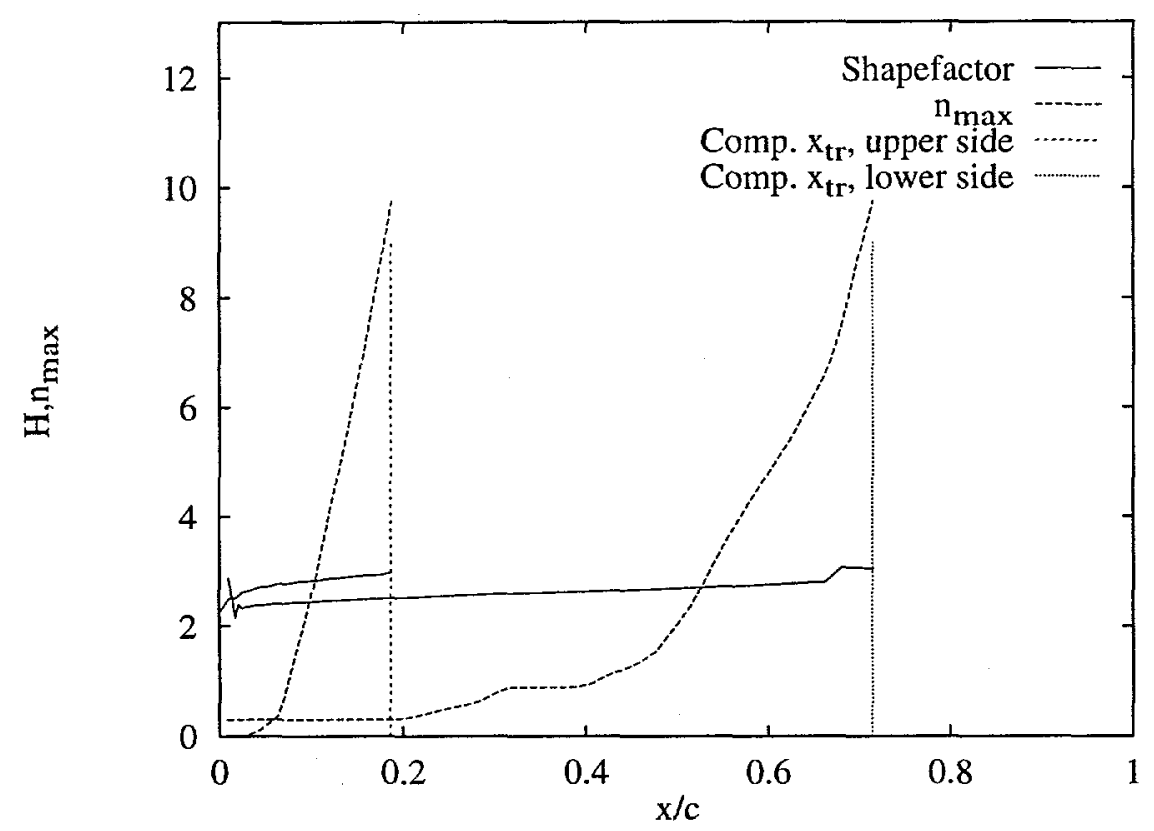

Figure 5. Shape factor, $H, n_{\max }$, and transition point location, $x_{t r}$, for both upper and lower side NACA0012, $\alpha=3^{\circ}$, Re $=3 \times 10^{6}$

Figure 5 shows the shape factor, $H$ and the growth of the $n$ factor on both upper and lower side of the airfoil. Compared to the flat plate case, figure 2, the shape 
factor increases due to the adverse pressure gradient. This causes the $n$ factor to grow faster on the upper side where pressure gradient is larger. The onset of transition is where the $n$ factor reaches the value 9 .

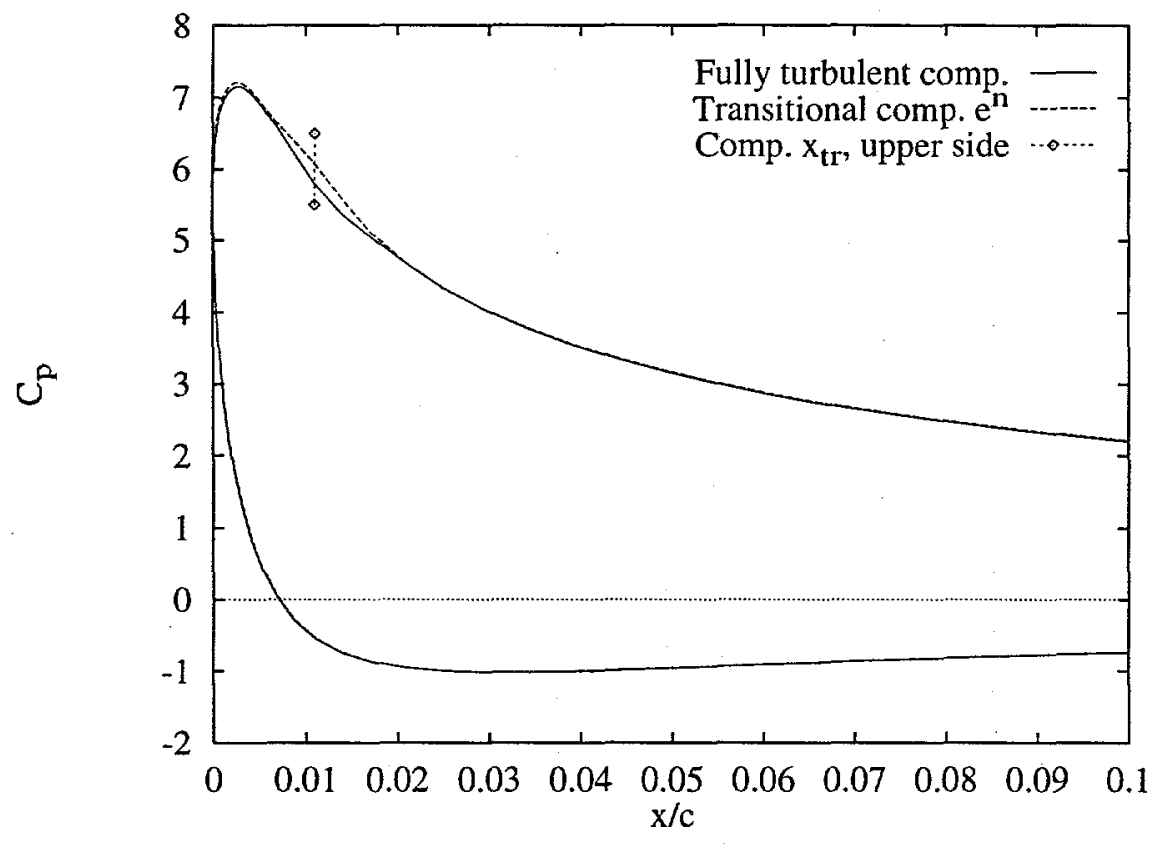

Figure 6. Pressure distribution, $C_{p}$, for fully turbulent flow compared with transitional flow and computed transition point location, $x_{t r}, N A C A 0012, \alpha=12^{\circ}$, $R e=3 \times 10^{6}$

The pressure distribution for $\alpha=3 \times 10^{\circ}$ shows no difference between fully turbulent and transitional computation. But, as seen from figure 6 the transition point has a small effect on the pressure distribution at $\alpha=12^{\circ}$. This is caused by the leading edge separation bubble, where the pressure gradient approaches zero in separated regions.

The skin friction shown in figures 7 and 8 shows a clear difference between fully turbulent and transitional computation. This underlines the importance of transition point prediction when computing drag characteristics. Looking at the skin friction for $\alpha=12^{\circ}$, figure 8 , it is seen that the linear stability model predicts transition well into the laminar separation bubble, which corresponds well with experimental data, where the separation occurs in the laminar region and reattaches in the turbulent region.

Figures 9 and 10 shows the lift and drag curves respectively, computed with fully turbulent flow and using the two different transition prediction models compared with experimental data. The lift curve shows hardly any difference between the fully turbulent and the transitional computations, whereas the drag curves shows much better predictions using transitional computations. This again underlines the effect of transition point prediction, when considering drag characteristics. There is no significant difference between the two transition models.

Table 1 shows the computed transition point locations using both the Michel criterion and the $e^{n}$ model compared with experimental data. 


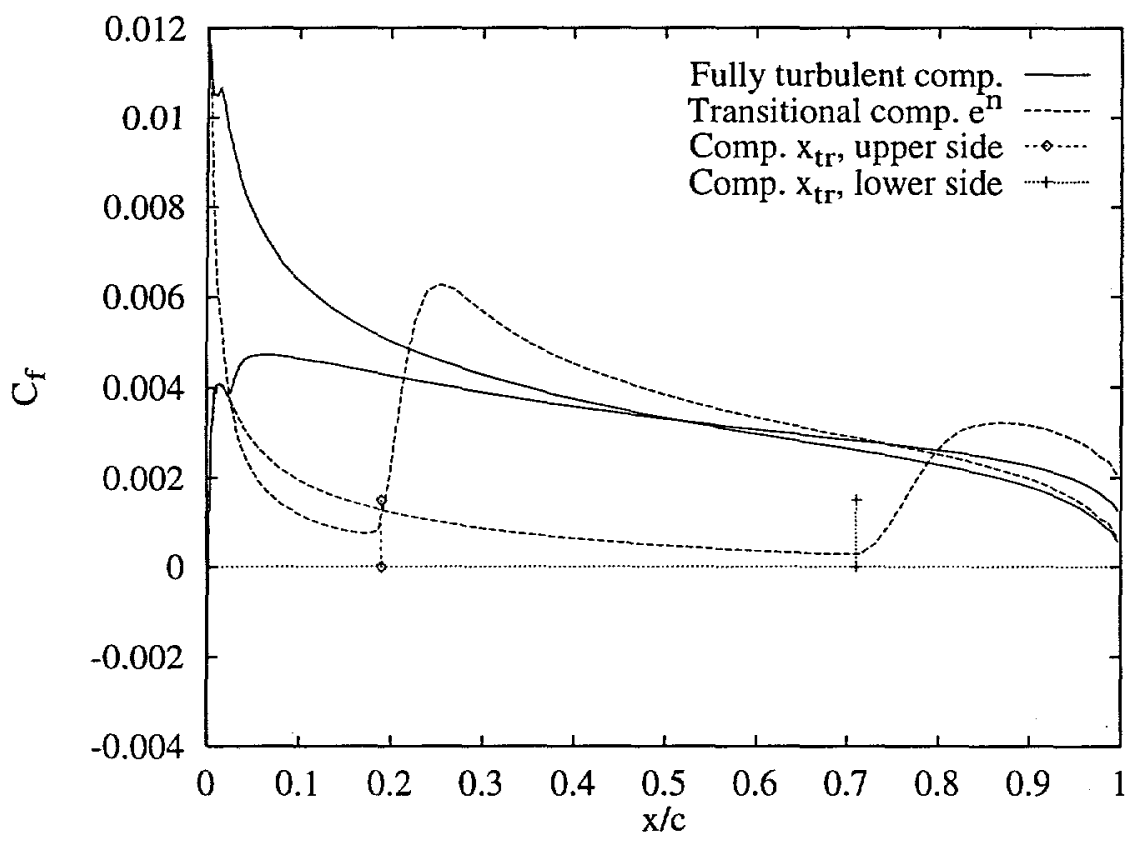

Figure 7. Skin friction, $C_{f}$, for fully turbulent flow compared with transitional flow and computed transition point location, $x_{t r}, N A C A 0012, \alpha=3^{\circ}, R e=3 \times 10^{6}$

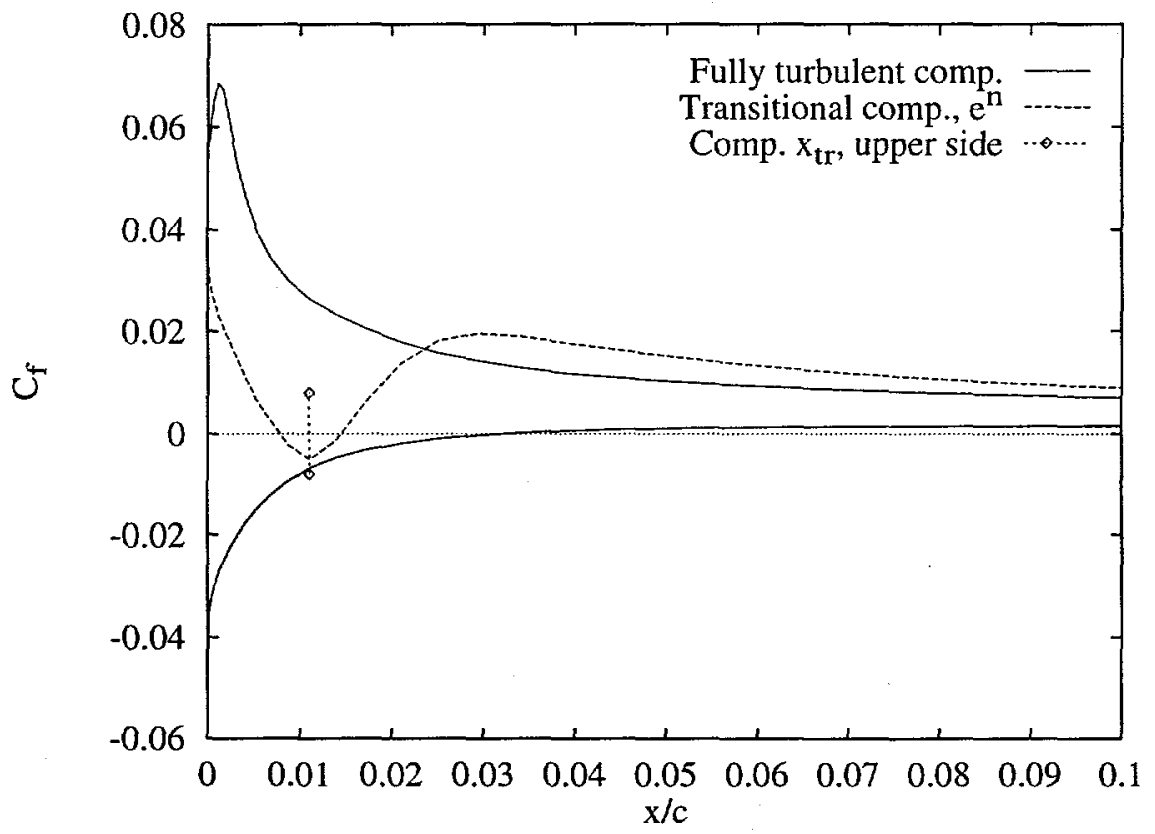

Figure 8. Skin friction, $C_{f}$, for fully turbulent flow compared with transitional flow and computed transition point location, $x_{t r}, N A C A 0012, \alpha=12^{\circ}, R e=3 \times 10^{6}$ 


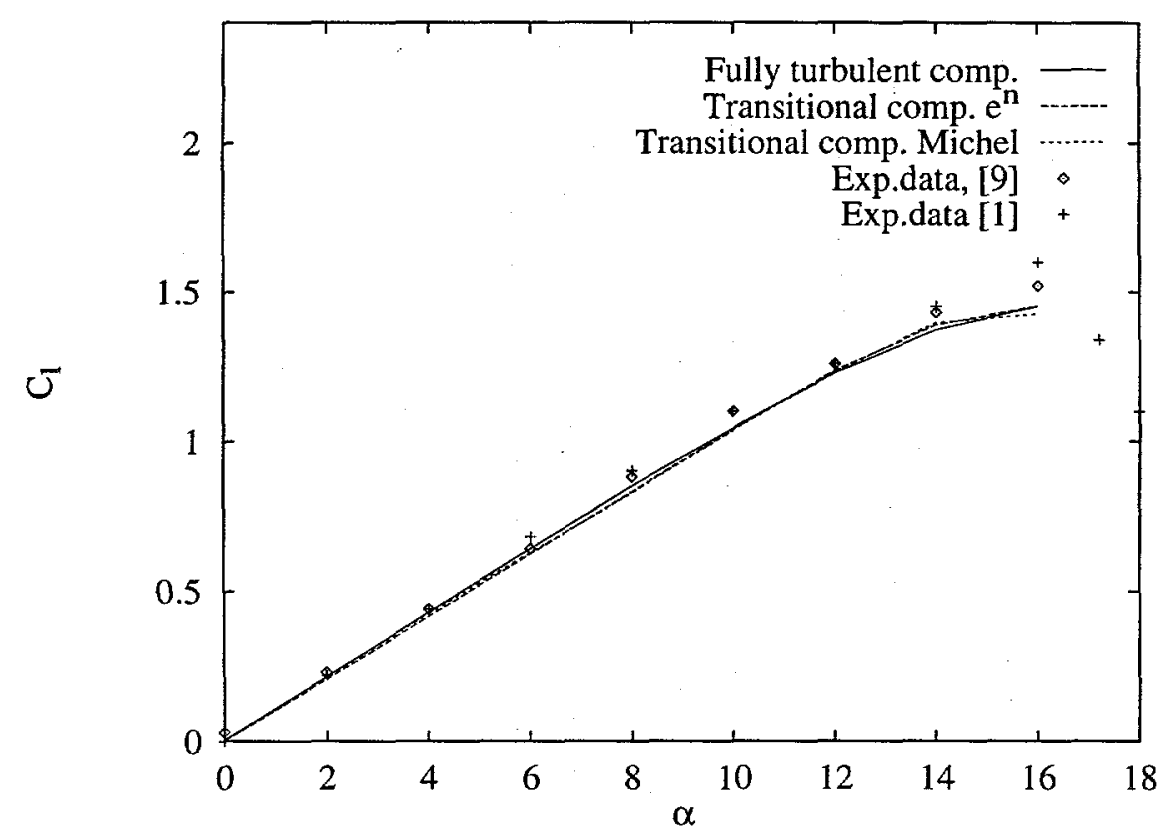

Figure 9. Lift curve for fully turbulent flow compared with transitional flow and experimental data, [9], NACA0012, Re $=3 \times 10^{6}$

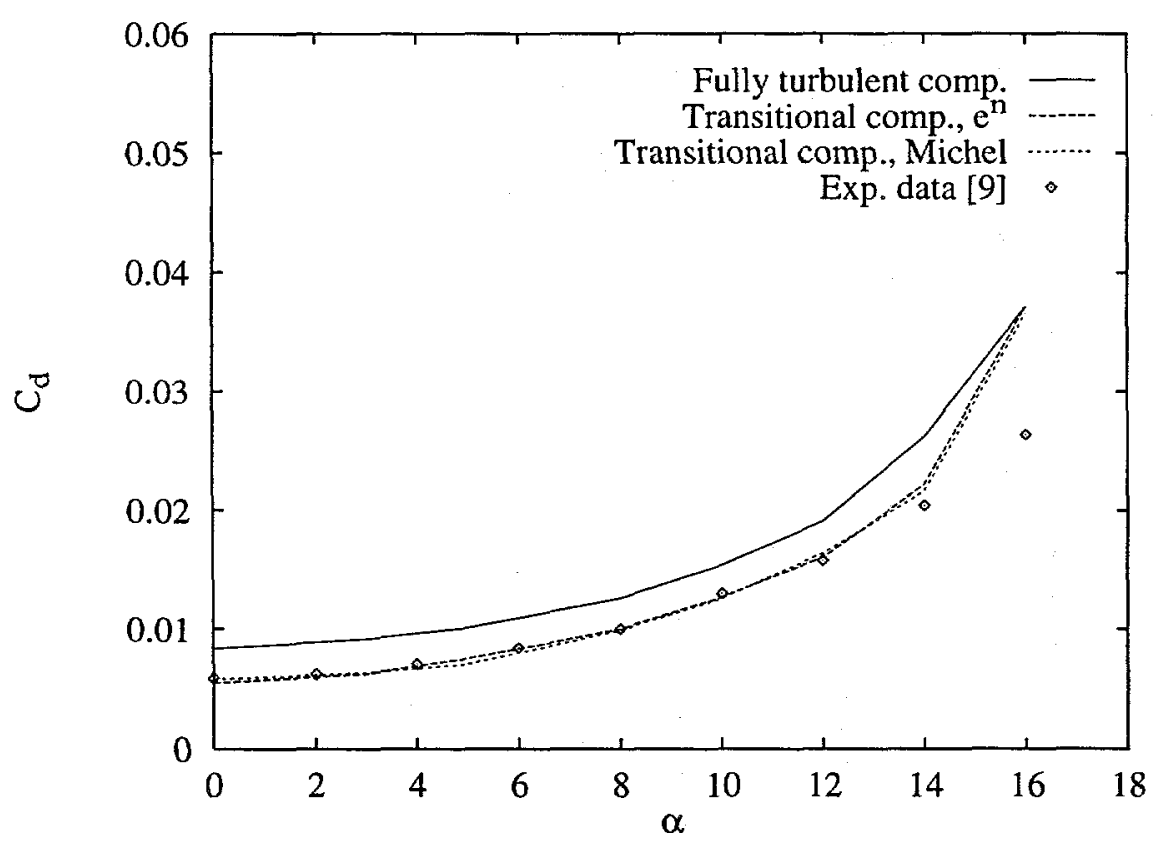

Figure 10. Drag curve for fully turbulent flow compared with transitional flow and experimental data, [9] NACA0012, Re $=3 \times 10^{6}$ 
Table 1. Transition point locations for the NACA0012 airfoil, $R e=3 \times 10^{6}$

\begin{tabular}{c|ccc|ccc}
$\alpha$ & \multicolumn{3}{|c|}{$x_{t r_{\text {up }}}$} & \multicolumn{3}{|c}{$x_{\text {tr }_{\text {low }}}$} \\
\hline & $\exp$ & $e^{n}$ & Michel & $\exp$ & $e^{n}$ & Michel \\
\hline 0 & 0.45 & 0.44 & 0.43 & 0.45 & 0.44 & 0.43 \\
3 & 0.20 & 0.19 & 0.21 & 0.66 & 0.68 & 0.72 \\
5 & 0.085 & 0.060 & 0.13 & 0.79 & 0.84 & 0.88 \\
8 & 0.024 & 0.025 & 0.070 & 0.92 & 0.99 & 1.00 \\
10 & 0.013 & 0.014 & 0.040 & 1.00 & 1.00 & 1.00 \\
12 & - & 0.012 & 0.014 & 1.00 & 1.00 & 1.00 \\
\hline
\end{tabular}




\subsection{FX66-S-196 V1 Airfoil}

The previous test case are computed at a relatively high Reynolds number, where no large difference is observed between the to transition models. At more moderate Reynolds numbers where transitional effects are more pronounced a larger difference would be expected.

The lift and drag curves of the $19 \%$ thick FX 66-S-196 V1 airfoil are shown in figures 11 and 12 .

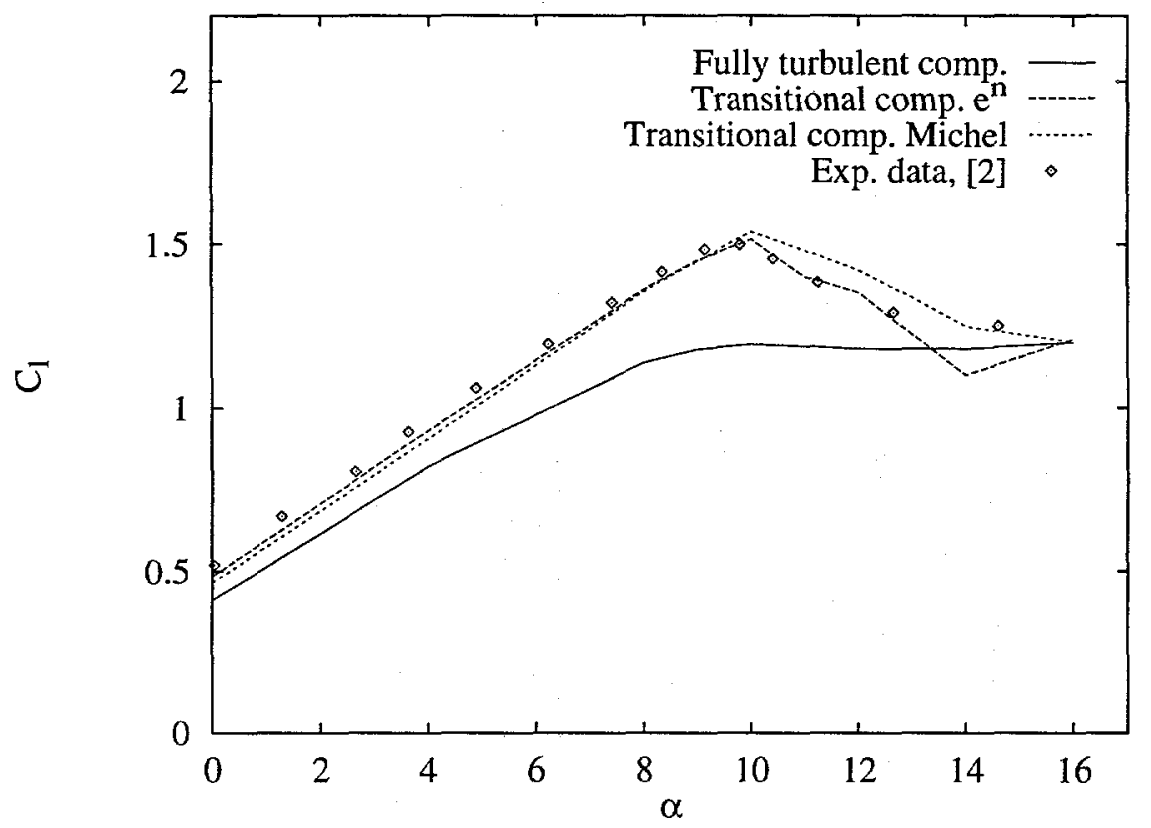

Figure 11. Lift curve for fully turbulent flow compared with transitional flow and experimental data, [2], FX 66-S-196 V1, Re $=1.5 \times 10^{6}$

The fully turbulent computation is surely not acceptable; using the transition prediction models gives better results. Both transition models predict the maximum lift well, but at light stall the $e^{n}$ model is superior. At high angles of attack the transition point on the suction side approaches the leading edge, i.e. the lift approaches the fully turbulent value. The relatively poor prediction of lift at $\alpha=14^{\circ}$ is a consequence of a transition point moving up- and downstream very close to the leading edge. This results in a varying lift with an average value lower than if the transition point was stable. At $\alpha=16^{\circ}$ the flow is fully turbulent on the suction side.

From the pressure distribution in figure 13 , for $\alpha=8^{\circ}$, it is seen that the transition point affects $C_{p}$ globally and not locally as seen for the NACA0012 airfoil. The reason for this is that the Wortmann airfoil is a laminar airfoil, where transition takes place further downstream. As seen on figures 13 and 14 , the transition on the suction side takes place at $x_{t r}=0.45$ which causes a large part of the flow around the airfoil being laminar, and therefor a large deviation from fully turbulent flow is obtained. The skin friction distribution in figure 14 shows a small separation where transition takes place. The large effect of transition causes the fully turbulent flow to under predict lift, figure 11 and over predict drag, figure 12 .

The computed transition points are shown in table 2. At lower angles of attack no large difference is observed on the upper side. But as the angle of attack increases the $e^{n}$ model gives slightly better results. On the lower side the Michel 


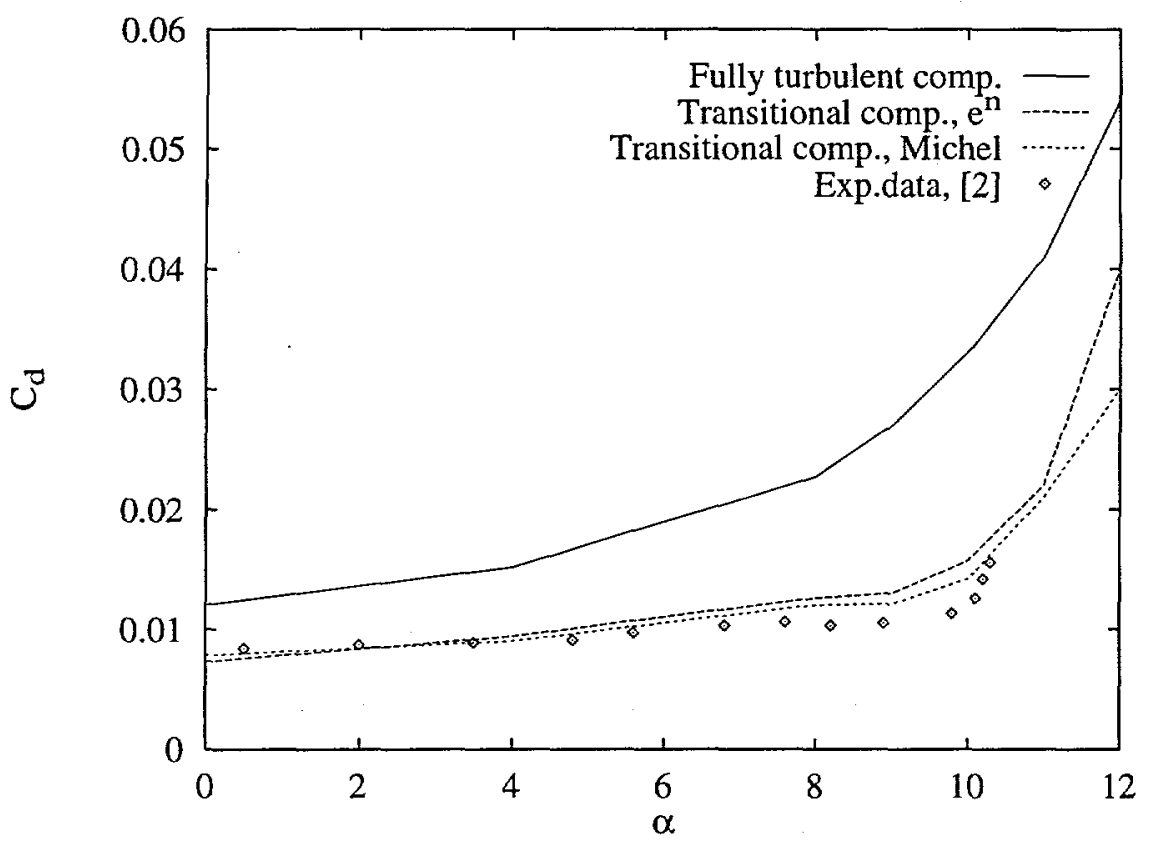

Figure 12. Drag curve for fully turbulent flow compared with transitional flow and experimental data, [2], FX 66-S-196 V1, Re $=1.5 \times 10^{6}$

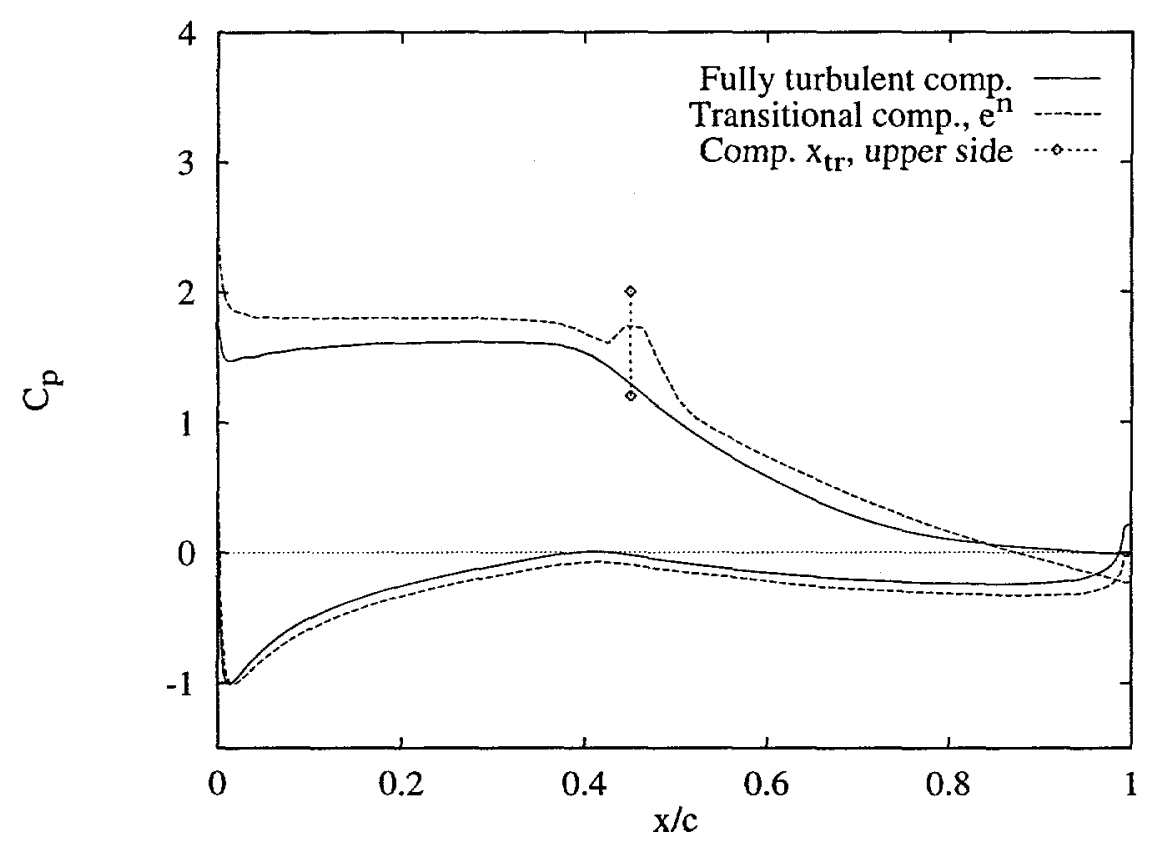

Figure 13. Pressure distribution, $C_{p}$, for fully turbulent flow compared with transitional flow and computed transition point location, $x_{t r}, F X 66-S-196 \mathrm{V1}, \alpha=8^{\circ}$, $R e=1.5 \times 10^{6}$

model shows an unstable behaviour, whereas the $e^{n}$ model is more stable and gives better predictions. 


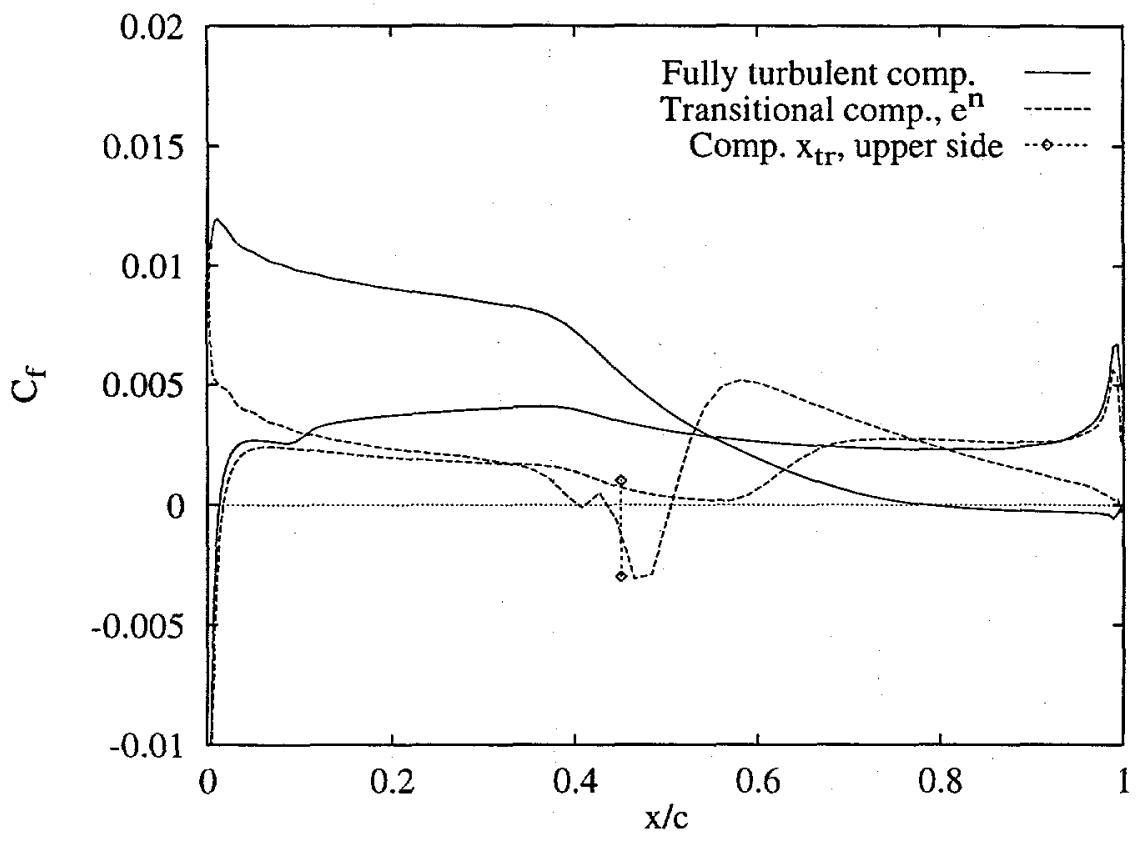

Figure 14. Skin friction, $C_{p}$ for fully turbulent flow compared with transitional flow and computed transition point location, $x_{t r}, F X 66-S-196 V 1, \alpha=8^{\circ}, R e=$ $1.5 \times 10^{6}$

Table 2. Transition point locations for the FX 66-S-196 V1 airfoil, Re $=1.5 \times 10^{6}$

\begin{tabular}{c|ccc|ccc}
$\alpha$ & \multicolumn{3}{|c|}{$x_{t r_{u p}}$} & \multicolumn{3}{|c}{$x_{t r_{l o w}}$} \\
\hline & $\exp$ & $e^{n}$ & Michel & $\exp$ & $e^{n}$ & Michel \\
\hline 0 & 0.53 & 0.48 & 0.50 & 0.50 & 0.45 & 0.50 \\
4 & 0.50 & 0.48 & 0.48 & 0.54 & 0.51 & $0.69 \pm 0.17$ \\
8 & 0.46 & 0.45 & 0.41 & 0.60 & 0.56 & $0.82 \pm 0.18$ \\
9 & 0.45 & 0.39 & 0.39 & 0.62 & 0.59 & 0.90 \\
10 & 0.27 & 0.32 & 0.35 & 0.66 & 0.61 & 1.00 \\
11 & - & 0.27 & 0.30 & - & 0.70 & 1.00 \\
12 & - & 0.20 & 0.25 & - & 0.75 & 1.00 \\
\hline
\end{tabular}

\section{Conclusion}

In the present study a simplified version of the $e^{n}$ transition model was coupled with a Navier-Stokes solver applied in low Reynolds number airfoil flows. A two-equation integral laminar boundary layer formulation was solved using a direct/inverse formulation in order to determine integral boundary layer parameters. The inverse procedure was chosen first of all to get integral parameters well into the separated region, but also to overcome the difficulty of defining the velocity at the edge of the boundary layer, $u_{e}$. Comparisons with the simple empirical Michel criterion and with experimentally determined transition point locations have been made for flow over a flat plate and for flow around airfoils. For flat plate flow good agreement with literature was achieved. The $e^{n}$ model based on linear stability theory has the strength of taking streamwise pressure gradients into account, which occurs in airfoil flows. The results discussed in the present study indicate that proper transition point prediction is crucial, especially when considering the drag characteristics. The computations of the NACA0012 airfoil 
at high Reynolds number show a minor effect on the lift prediction while the drag characteristics are more influenced. The computations of the FX 66-S-196 V1 airfoil at moderate Reynolds number clearly show the importance of transition prediction for both lift and drag characteristics. At low angles of attack no large difference were observed between the two transition models, but for higher angles of attack the simplified version of the $e^{n}$ model showed better agreement with experimental data. The Reynolds numbers under investigation is relatively high in order to see a large influence on transition. A future investigation will be addressed to airfoils at lower Reynolds numbers where larger transitional effects are present. The computational time using the simplified version of the $e^{n}$ model is not larger than using the Michel criterion. This model is therefore superior to the empirical model and therefore preferable.

\section{References}

[1] Aвbott, I. H., and von Doenhoeff, A. E. Theory of Wing Sections. Dover Publications, Inc., New York, 1959.

[2] Althaus, D., and Wortmann, F. X. Stuttgarter Profilkatalog 1. Tech. rep., F. Wieweg, Braunschweig, 1981.

[3] Arnal, D. Boundary Layer Transition: Predictions based on Linear Theory. Tech. rep., AGARD, 1994. AGARD-R-793.

[4] CebecI, T. Essential Ingridients of a Method for Low Reynolds-Number Airfoils. AIAA 27, 12 (1988).

[5] Chen, K. K., and Thyson, N. A. Extension of Emmons Spot Theory to Flows on Blunt Bodies. AIAA 9, 5 (1971), 821-825.

[6] Dini, P., Selig, M. S., and Maughmer, M. D. Simplified Linear Stability Transition Prediction Method for Separated Boundary Layers. AIAA 30, 8 (1992), 1953-1961.

[7] Drela, M., AND Giles, M. B. Viscous-Inviscid Analysis of Transonic and Low Reynolds Number Airfoils. AIAA 25, 10 (1986).

[8] Ekaterinaris, J. A., Chandrasekhara, M. S., and Platzer, M. F. Analysis of Low Reynolds Number Airfoil Flows. Journal of Aircraft (1995), 625-630.

[9] Gregory, N., ANd O'Reilly, C. L. Low-Speed Aerodynamic Characteristics of NACA0012 Airfoil Section, Including the Effects of Upper-Surface Roughness Simulating Hoar Frost. Tech. rep., NPL AERO Rept. 1308, 1970.

[10] Mehta, U., Chang, K. C., and Cebeci, T. Relative Advantages of ThinLayer Navier-Stokes and Interactive Boundary-Layer Procedures. Tech. rep., NASA, 1985. Technical Memorandum.

[11] Menter, F. R. Zonal Two Equation $k-\omega$ Turbulence Models for Aerodynamic Flows. AIAA Paper 93-2906.

[12] Miches, R. Etude de la Transition sur les Profiles d'Aile;Etablissement d'un Critére de Determination de Point de Transition et Calcul de la Trainee de Profile Incompressible. Tech. rep., ONERA, 1951. Report 1/1578A.

[13] Michelsen, J. A. Basis3D - a Platform for Development of Multiblock PDE Solvers. Tech. rep., Technical University of Denmark, 1992. AFM 92-05. 
[14] Michelsen, J. A. Block structured Multigrid solution of 2D and 3D elliptic PDE's. Tech. rep., Technical University of Denmark, 1994. AFM 94-06.

[15] Olesen, N. A. Laminar/turbulent Omslagsmodel for Grænselagsstrømninger. Master's thesis, Danish Technical University, 1994. AFMEP 94-02.

[16] Petersen, E. D. Grænselagsstabilitet. Master's thesis, Danish Technical University, 1991. AFM-EP 91-01.

[17] Schlichting, H. Boundary-Layer Theory. McGraw-Hill, Inc., 1987.

[18] Smith, A. Transition, Pressure Gradient, and Stability Theory. In Proceedings of the IX International Congress of Applied Mechanics (1956), vol. 4, pp. 234-244.

[19] Sørensen, N. N. General Purpose Flow Solver Applied to Flow over Hills. Tech. rep., Risø National Laboratory, Roskilde, Denmark, June 1995. RisøR-827(EN).

[20] STock, H., AND Degenhart, E. A simplified $e^{n}$ method for transition prediction in two-dimensional, incompressible boundary layers. Z. Flugwiss. Weltraumforsch. 13 (1989).

[21] VAN Ingen, J. A Suggested Semi-empirical Method for the Calculation of the Boundary-Layer Region. Tech. rep., Delft,Holland, 1956. Rept. No. VTH71, VTH74. 
Title and author(s)

Prediction of Laminar/Turbulent Transition in Airfoil Flows

Jeppe Johansen

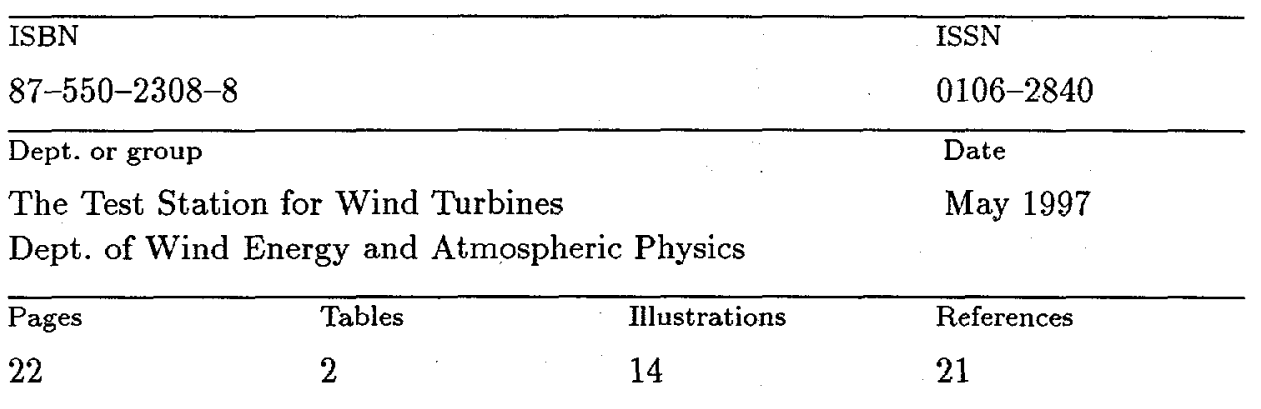

Abstract (Max. 2000 char.)

The prediction of the location of transition is important for low Reynolds number airfoil flows. The laminar/turbulent properties of the flow field have an important influence on skin friction and separation and therefore on lift and drag characteristics. In the present study the more general $e^{n}$ model, is compared to the Michel criterion. The $e^{n}$ method is based on linear stability analysis employing the OrrSommerfeld equation to determine the growth of spatially developing waves. In order not to compute growth rates for each velocity profile, a database, with integral boundary layer parameters as input, has been established. The problem of determining boundary layer properties using a Navier-Stokes solver, is solved using a two-equation integral formulation, which are solved using a direct/inverse Newton-Raphson method. The test cases under investigation are incompressible transitional flow over a flat plate and around airfoils at low and moderate Reynolds numbers, at fixed angles of attack, varying from attached flow through light stall. At high Reynolds numbers no large difference is observed between the two transition models. But for lower Reynolds numbers, the $e^{n}$ method shows better agreement with experiments. Furthermore it has shown to be more stable. It is therefore preferable to the empirical transition model.

Descriptors INIS/EDB

Aerodynamics; Airfoils; Boundary Layers; Drag; Flow Models; Friction; Laminar Flow; Turbulent Flow

Available on request from:

Information Service Department, Ris $\varnothing$ National Laboratory

(Afdelingen for Informationsservice, Forskningscenter Ris $\emptyset$ )

P.O. Box 49, DK-4000 Roskilde, Denmark

Phone (+45) 46774677 , ext. 4004/4005. Fax (+45) $46755627 \cdot$ Telex 43116 